\begin{tabular}{|c|c|}
\hline Title & A moving middle finger \\
\hline Author(s) & Sudo, Hideki; Ito, M.; Minami, A. \\
\hline Citation & $\begin{array}{l}\text { The L ancet, 361(9376), } 2202 \\
\text { https://doi.org/10.1016/\$0140-6736(03)137749 }\end{array}$ \\
\hline Issue Date & $2003-06-28$ \\
\hline Doc URL & http:/hdl.handle.net/2115/14597 \\
\hline Type & article (author version) \\
\hline File Information & Lancet2003-361-9376.pdf \\
\hline
\end{tabular}

Instructions for use 


\section{A moving middle finger}

Hideki Sudo, MD

Manabu Ito, MD

Akio Minami, MD

Department of Orthopaedic Surgery, Hokkaido University Graduate School of Medicine, Sapporo, Japan.

Correspondence;

Hideki Sudo, MD

Department of Orthopaedic Surgery

Hokkaido University Graduate School of Medicine

North-15, West-7, Kita-ku

Sapporo, Hokkaido 060-8638, Japan

Phone:+81-11-706-5934 FAX:+81-11-706-6054

E-mail: hidekisudo@yahoo.co.jp 
A 56-year-old female care worker presented in June 2002, with a history of burning hot pain in her right forearm followed by involuntary movement of the right middle finger. She had a history of diabetes mellitus and hypertension; however, these were well controlled by medication. The past history was unremarkable. She did not have relevant family history. The movements of the finger were continuous, purposeless and consisted of extension-flexion combined with abduction-adduction, which could be temporarily stopped by voluntary efforts, but could not be stopped by this method for very long. Physical examination showed tenderness in her right humeral epicondyle. Deep tendon reflex and the muscle strength of both upper limbs were normal, disesthesia in her right forearm was observed but it did not correspond to sensory dermatome. Routine laboratory blood studies for rheumatoid factor, radiograph and angiograph of the forearm were normal. Peripheral nerve conduction velocity and electromyography were normal. We firstly suspected that the symptom might be associated with an epicondylalgia. The patient was treated with an analgesic, baclofen, carbamazepine, or benzodiazepine, but nothing proved effective. Subcutaneous injection with mepivacaine and dexamethasone was performed but also proved ineffective.

Her symptoms progressively worsened and the burning pain spread to both her whole arms. Magnetic resonance imaging showed a mild spinal canal stenosis of the cervical spine compressing the spinal cord at the C4-5 and C5-6 level (figure). A pain in C7 dermatome became clear with a progress of time. There was a possibility that her symptoms were associated with a segmental lesion of the spinal cord due to the spinal cord compression at the C5-6 level. Cervical traction decreased the symptom, but was not sufficient. Epidural block and stellate ganglion block using mepivacaine were performed, improving the pain and movement in both arms. However, the effectiveness of the injection treatment did not last more than several days. At last, she underwent bilateral open door laminoplasty to decompress the spinal cord from the back. 
After surgery, her burning pain and involuntary movement disappeared. When last seen in June 2003, she did not complain of the previous symptoms.

A syndrome of painful arms and moving fingers is rare (only two cases reported). It has been reported that this had occurred after a brachial plexus lesion due to radiotherapy or after trauma and amputation., ${ }^{1,2}$ The pain in the upper extremity is burning and usually precedes the movements. The involuntary movement of the fingers is continuous, purposeless, and sometimes similar to athetosis or pseudo-athetosis due to sensory polyneuropathy. ${ }^{1}$ Sometimes the movement stops during sleep. ${ }^{2}$ The diagnosis can be difficult, because the clinical presentation is highly non-specific except for the involuntary finger movement. Similar cases involving lower extremities are more common and recognized as painful leg and moving toes, and some of these cases are due to radicular lesions or peripheral nerve lesions caused by lumbar disc herniation, or traumatic nerve injuries. ${ }^{3,4}$ Though the mechanism of the involuntary digit movement remains unclear, it can be speculated that a cervical lesion compressing the afferent fibers of the posterior nerve roots or the spinal cord causes continuous impulses or stimulations to produce uncoordinated movements in local muscles in the upper extremities. ${ }^{4}$ The differential diagnosis includes reflex sympathetic dystrophy, parkinsonian tremor, thoracic outlet syndrome, cubital tunnel syndrome, and diabetic neuropathy. Detailed clinical examinations, detection of neural compression by imaging technologies, and awareness of this syndrome can help aid the diagnosis. Treatment should be started with conservative measures including rest, analgesic, and physiotherapy. Surgical treatment is indicated for the cases irresponsive to prolonged conservative treatment. 


\section{References}

1 Verhagen W, Horstink M. Painful arm and moving fingers. J Neurol Neurosurg Psychiatry 1985; 48: 384-85.

2 Funakawa I, Mano Y, Takayanagi T. Painful hand and moving fingers: A case report. J Neurol 1987; 234:342-43.

3 Okuda Y, Suzuki K, Kitajima T, Masuda R, Asai T. Lumbar epidural block for ‘ painful legs and moving toes’ syndrome: a report of three cases. Pain 1998;78: 145-47.

4 Nathan P.W. Painful legs and moving toes: evidence on the site of the lesion. $J$ Neurol Neurosurg Psychiatry 1978; 41: 934-39. 


\section{Acknowledgement}

We thank Nozomu Hujimoto, internist, Sapporo Teishin Hospital, for introduction of the patient and helpful discussions.

\section{Figure Legend}

Spinal magnetic resonance image showing spinal canal stenosis

\section{Author's contributions}

H Sudo were in charge of the patient.

H Sudo and M Ito did surgical treatment.

All authors contributed to writing the report.

Conflict of interest statement and Role of the funding source

There are no conflicts of interest and funding. 


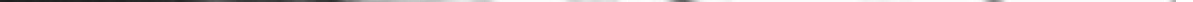

